\title{
Leading the charge: Médecins Sans Frontières receives the 2015 Lasker Bloomberg Public Service Award
}

$T_{\text {he }}$ 2014 Ebola outbreak in West Africa has been unprecedented in many respects, including its geographical spread, the number of individuals infected, and duration. Médecins Sans Frontières (MSF, also known as Doctors Without Borders) was among the first organizations to respond to early reports of a hemorrhagic fever of unknown origin in Guinea. MSF called upon the international community to act early during the outbreak, but these early warnings were largely dismissed or thought to be overstated. MSF responders have worked tirelessly and continue to do so to provide care to those infected with Ebola, to educate affected communities, and to support local healthcare providers. For their bold leadership and unwavering support during the current Ebola outbreak in West Africa and their continued efforts to provide health care to people in crisis throughout the world, MSF is being recognized with the 2015 Lasker Bloomberg Public Service Award (Figure 1).

\section{Impartial aid for those that need it most}

MSF was established in 1971 by a group of French doctors and journalists with the goal of providing aid and improving the welfare of patients in crisis, regardless of race, religion, politics, or ideology. The founders of MSF were inspired to act after witnessing the devastation and the restrictions placed on international aid organizations trying to provide care and food to those within the secessionist state of Biafra in southeastern Nigeria. The organization focuses on providing emergency relief and has launched campaigns all over the world to provide medical treatment to people affected by war, disease, political instability, and natural disasters. In this capacity, MSF also bears witness to the atrocities their patients face and have been outspoken advocates throughout their history. Since its inception, MSF has treated over 100 million patients and currently has

programs underway in some 70 countries. MSF prioritizes its resources to the areas of greatest need and often leads the charge to provide medical care in response to national disasters, refugee crises, war, and disease outbreaks (1).

In early 2014, MSF focused large-scale efforts on providing care for individuals suffering as a result of conflicts in South Sudan, the Central African Republic, and Syria. Then, in March of that year, the organization was notified that the Ministry of Health in Guinea had reported the presence of a mysterious disease with a high incidence of mortality. Patients presented with severe fever, vomiting, and diarrhea, and the disease readily spread to those that

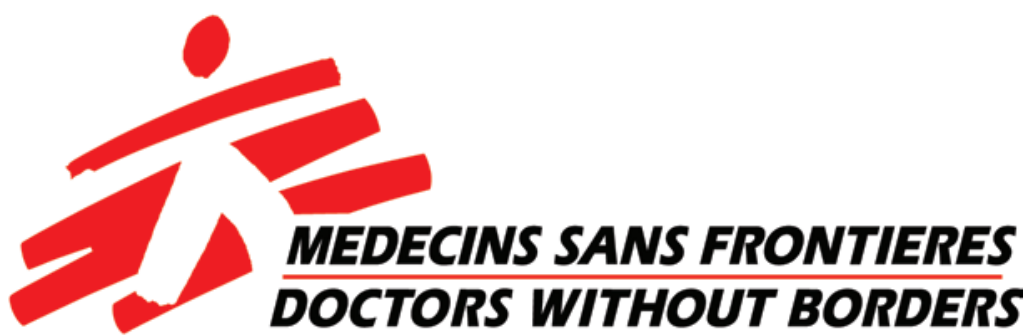

Figure 1. MSF is honored with the 2015 Lasker Bloomberg Public Service Award.

directly cared for the sick and/or assisted in burial of the dead. As the symptoms pointed to a hemorrhagic fever virus, such as Ebola or Lassa, MSF deployed teams of emergency responders to Guinea that included individuals with experience dealing with these deadly viruses. The first MSF team arrived in Guéckédou, Guinea on March 18, 2014. Four days later, on March 22, 2015, Ebola was confirmed as the cause of disease, and the Guinean Ministry of Health officially declared an Ebola outbreak (2).

\section{Ebola in sub-Saharan Africa}

Ebola virus was first isolated in the late 1970s and determined to be the causative agent of hemorrhagic fever outbreaks in the Democratic Republic of the Congo (DRC) and Sudan (3). These initial epidemics were striking due to the highly contagious nature of the disease and the extreme mortality; however, by the time international aid organizations had arrived to help the affected communities, transmission of the disease had largely subsided. Multiple factors contributed to containment of the Ebola virus in these communities. Infected individuals had been quarantined in their villages, preventing spread to other communities. Additionally, there was a widespread closure of medical facilities due to the high incidence of infection among local healthcare providers. The virus would not appear again in human communities until 1994 $(4,5)$. Since 1994, most Ebola epidemics have occurred in central and east African countries and have largely been restricted to remote rural areas.

The primary host and natural reservoir of Ebola has not been definitively identified; however, the virus has been isolated from a variety of animals, including bats, rodents, duikers, pigs, and nonhuman primates, that can travel relatively large distances (4). Transmission of the Ebola virus to humans is incidental and occurs through direct contact with blood and other secretions from encounters with animals harboring the virus. Infected individuals spread the disease to those that come in direct contact with bodily fluids, which contain high titers of Ebola virus when symptoms are present (6). Treat- 


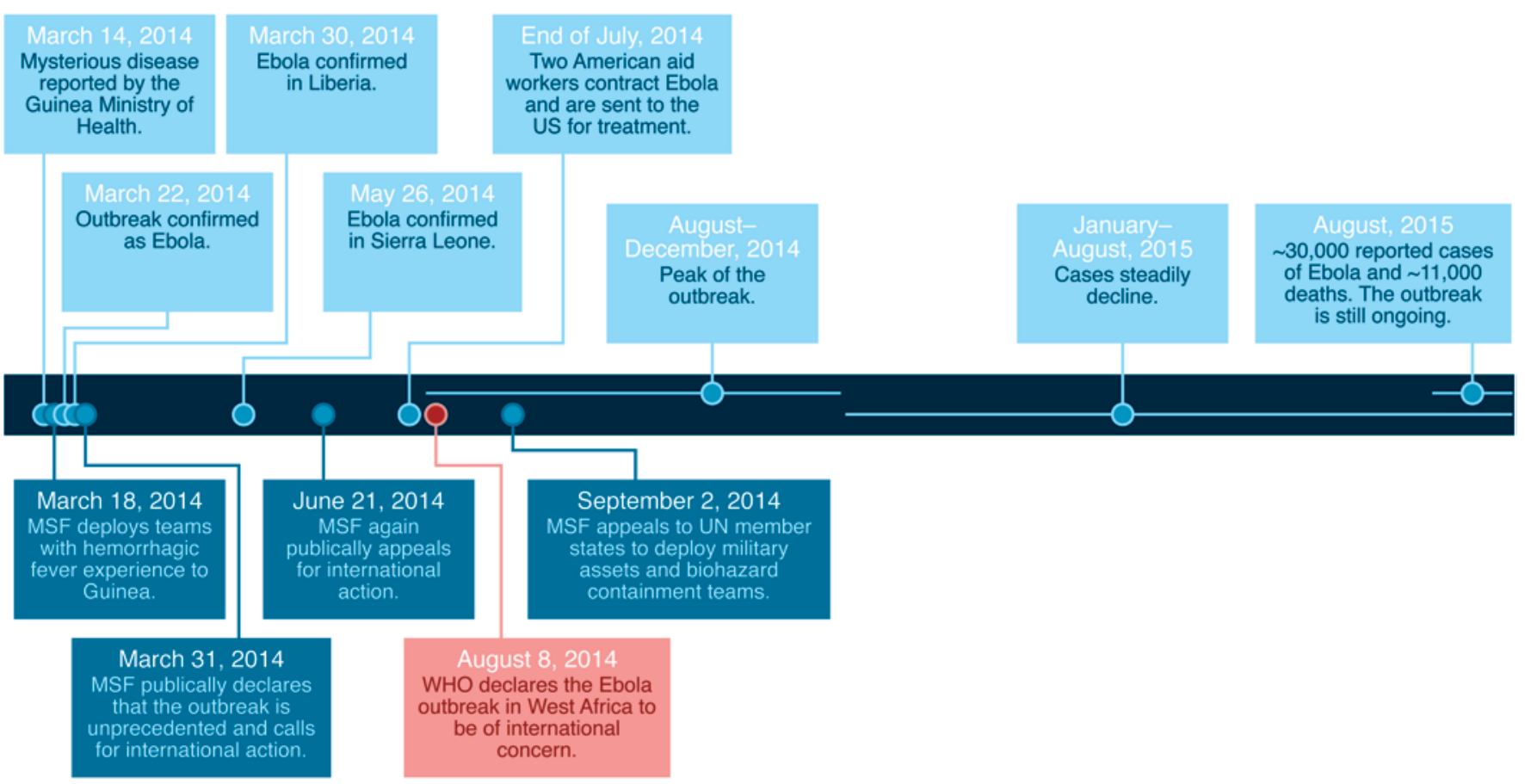

Figure 2. A timeline of the Ebola outbreak in West Africa and the response by MSF. MSF responded early to the outbreak and immediately recognized the extraordinary nature of this epidemic. Despite early warnings and appeals to the international community, it would be months after the first confirmed cases before the WHO would declare the outbreak as a public health emergency of international concern. Ebola is on the decline in West Africa; however, much work remains to be done to restore the healthcare systems in the affected communities and ensure that the outbreak ends.

ment is largely palliative, as there are no known cures for the disease. The success of supportive therapy is largely dependent on when the patient first receives care and his or her immune response.

\section{Ebola moves west}

Over the last 20 years, MSF has been involved in the control of Ebola outbreaks in 9 central African countries. Based on their experience with these previous outbreaks, MSF has identified 6 key steps for controlling an Ebola outbreak: (a) isolate and care for patients; (b) institute safe burial practices; (c) educate local communities about the disease and how to protect themselves; (d) implement surveillance procedures to identify new cases of disease; (e) identify and follow up with anyone that had contact with a person infected with Ebola; and finally (f), maintain the ability to provide medical care for people with conditions other than Ebola (2). However, even this experience did not fully prepare the organization for the scale of the 2014 outbreak in West Africa (Figure 2).

Within days of the declaration of an Ebola outbreak by the Guinean Ministry of Health, MSF established their first
Ebola management center in Guéckédou, followed rapidly by the opening of a center hundreds of miles away in the Guinean capital, Conakry. The large distance between communities with suspected/ reported Ebola cases and the presence of people infected with the virus in urban areas made this outbreak distinct from any previous Ebola epidemic. On March 31, 2014, the MSF coordinator for the Conakry response, Mariano Lugli, publically declared, "We are facing an epidemic of a magnitude never before seen in terms of the distribution of cases in the country: Guéckédou, Macenta, Kissidougou, Nzérékoré, and now Conakry. This geographical spread is worrisome because it will greatly complicate the tasks of the organizations working to control the epidemic (7)." At this time, MSF called on the World Health Organization (WHO) and the Guinean government to ramp up efforts to isolate and treat patients showing possible signs of Ebola infection, follow up with potential contacts, raise awareness in communities, and train local healthcare workers to avoid infection (7). March would end with confirmation that this outbreak had moved beyond the borders of Guinea, as
Ebola was confirmed in Liberia (2). The international community largely ignored the call for more assistance and warnings that this outbreak had pandemic potential.

Throughout April and May of 2014, MSF continued their efforts to reduce the spread of Ebola in Guinea and Liberia. During this time, the number of new cases was declining and Ebola seemed to be coming under control. Then, on May 26, 2014, Ebola was confirmed in Sierra Leone, and it became clear that this outbreak was far from over. Now in three different countries, MSF was spread thin and priorities had to be redirected. There were not enough resources to implement all six phases of Ebola control. The organization focused their efforts on keeping local healthcare workers safe through enhanced training efforts and keeping Ebola management centers running (Figure 3). On June 21, 2014, MSF again warned that bringing the Ebola epidemic under control in West Africa would require massive deployment of government and international aid organization resources. In this report, MSF director of operations Dr. Bart Janssens warned, "The epidemic is out of control. With the appearance of new sites 


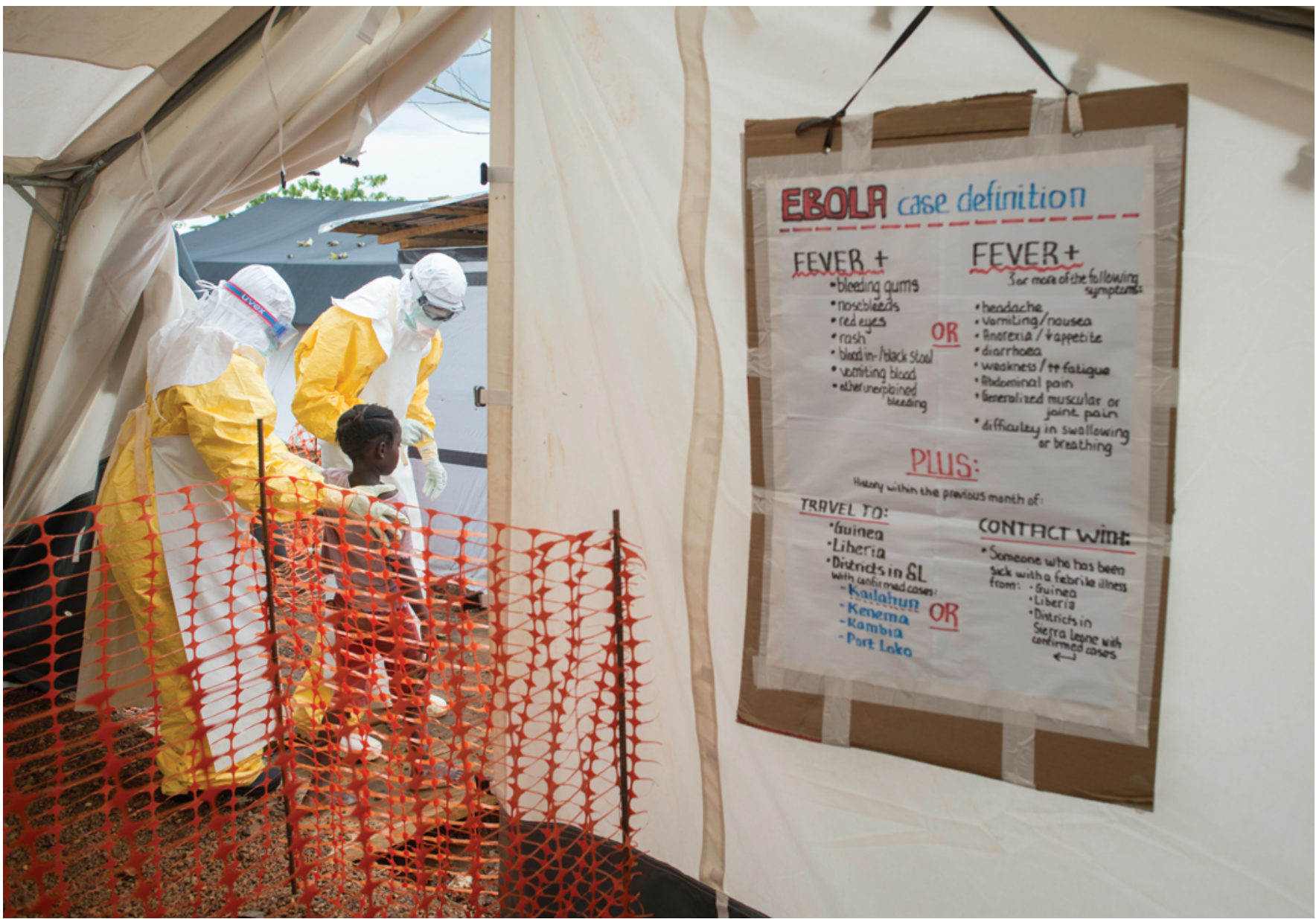

Figure 3. MSF Ebola treatment center in Kailahun, Sierra Leone. Photo courtesy of MSF. Image credit: Sylvain Cherkaoui/Cosmos.

in Guinea, Sierra Leone, and Liberia, there is a real risk of it spreading to other areas." By this time, 528 cases of Ebola had been reported and 337 deaths had been confirmed. Moreover, the scale and spread of the disease were causing anxiety and unrest in affected communities (8).

\section{Inadequate response to an international emergency}

Throughout June and July of 2014, MSF continued efforts to stem the tide of the Ebola outbreak. By this time, the number of confirmed cases in West Africa had risen to 1,093 cases with 660 deaths. As MSF had deployed the majority of its trained staff, the organization turned to other aid groups to assist in establishing and managing Ebola treatment centers. In July of 2014, MSF announced that the international relief organization Samaritan's Purse would be running a 40- to 60-bed facility to treat patients with Ebola in the Liberian capital, Monrovia (9). At the end of July 2014, Samaritan's Purse revealed that two of their team members, both American citizens, had been infected with Ebola while treating patients and would return to the US for isolation and treatment. The care and recovery of these volunteers thrust the West African Ebola outbreak into the international spotlight. On August 8, 2014, five months after Ebola was first confirmed in Guinea, the WHO officially declared that the Ebola outbreak in West Africa was an international public health emergency that required a coordinated global response to prevent international spread of the disease (10).

While the West African Ebola outbreak was propelled into the international spotlight, the international community was not prepared to respond to such an epidemic. Moreover, the WHO declaration led to the closing of borders and grounding of international flights to and from the affected regions. As August 2014 drew to an end, MSF President Thomas Nierle and Genera
Director Bruno Jochum derided the international response as slow and irresponsible. Not only were patients in these regions dying of Ebola, but also from malaria, diarrhea, childbirth complications, and other conditions due to the collapse of local healthcare systems and growing fear of contracting Ebola from healthcare providers. At this time, the international priority was to prevent the virus from spreading outside of West Africa and not on caring for patients (11). MSF international president Dr. Joanne Liu appealed to United Nations (UN) member states on September 2, 2014. "To curb the epidemic, it is imperative that states immediately deploy civilian and military assets with expertise in biohazard containment. I call upon you to dispatch your disaster response teams, backed by the full weight of your logistical capabilities. We cannot cut off the affected countries and hope this epidemic will simply burn out. To put out this fire, we must run into the burning building (2)." 
In August of 2014, MSF opened its largest Ebola response center, ELWA3, in Monrovia, Liberia. Within a week of opening, the center was at capacity, caring for 120 patients, and expansion of the facility was already underway (12). By September, the center would only be able to open its doors for 30 minutes each day and admit only a handful of people in need of care. Those that made it into the center replaced patients that had either been declared Ebola free or succumbed to the disease. At the UN special briefing on the Ebola outbreak in September 2014, Liu remarked, “Today, in Monrovia, sick people are banging on the doors of MSF Ebola care centers because they do not want to infect their families and they are desperate for a safe place in which to be isolated. Tragically, our teams must turn them away. We simply do not have enough capacity for them. Highly infectious people are forced to return home, only to infect others and continue the spread of this deadly virus. All for a lack of international response (13)." Jason Cone, executive director of MSF USA, recently told the JCI, "This mission probably affected some of our staff more than any mission they've done because many of our doctors had never faced so many patients dying. Every one of our medical personnel that I've been able to talk to always underscores how it pushed them beyond their limits of what they knew how to do as doctors and nurses, which was incredibly frustrating. You really can't underscore how almost humiliating the disease has been for medical providers, in the sense that we had so few tools to really make a difference"

\section{The disease recedes, but the damage is vast}

In October and November of 2014, international efforts began to materialize in the form of medical facilities to treat local and foreign aid workers and logistical support for international aid organizations. While these were not the biohazard teams to directly care for patients that MSF had called for, the efforts reassured local healthcare and aid workers that there were protections in place. As 2014 drew to an end, new cases of Ebola were declining and MSF was able to withdraw from some areas and hand over operations to other organizations and local communities (2).
The WHO reported that in 2014 there were 20,171 confirmed, probable, and suspected cases of Ebola that claimed the lives of 7,890 people (14).

In early 2015, as new cases of Ebola began to wane, MSF was able to expand outreach efforts, including enhanced surveillance of the disease, contact tracing, and education. Efforts have begun to reestablish healthcare systems in the affected regions so that people can regain access to malaria treatments, vaccines, and other essential services (2). As of August 9, 2015, there have been 27,929 reported confirmed, probable, and suspected Ebola cases throughout Guinea, Liberia, and Sierra Leone, with 11,283 reported deaths (15). For a region to be declared Ebola free, there must be no new reported, confirmed cases for 42 days. On May 9, 2015, Liberia, which had reported approximately 300 to 400 new cases per week at the peak of the outbreak, was declared free of Ebola transmission (16); however, new cases were reported in Liberia in June of 2015. Both Guinea and Sierra Leone are still reporting a handful of new cases per week, but with the reduced need for patient care, more resources can be put toward contact tracing and surveillance activities.

\section{Continued vigilance}

The Ebola outbreak is still not over and will not be until there are not any new cases of Ebola reported for 42 days. In a recent article, Liu remarked, "Ebola may have faded from the headlines, but it hasn't gone away. We don't know how far away the finish line is, but we do know that to reach it, everyone involved in the response - both national and international - needs to channel all their energies into keeping up the momentum. And by accelerating use of the new vaccine in the affected countries, we can help break chains of transmission and protect frontline workers. Our teams were there at the beginning. And like long-distance runners, we will stay to the end (17)."

As the Ebola outbreak begins to wane, it is clear that this epidemic has taken an incredible toll on the people of the affected countries. The healthcare systems in these regions are decimated. Prior to this epidemic, there were not adequate numbers of healthcare providers in these regions, and now nearly 500 workers have lost their lives due to Ebola. During the peak of the outbreak, people were unable to get treatment for other diseases, such as malaria and HIV, children did not receive important vaccinations, and women were not able to receive necessary assistance during childbirth (2).

MSF was founded to provide impartial medical service to populations in distress. The organization must constantly assess the needs of people throughout the world and determine how these needs should be prioritized. The Ebola outbreak in West Africa has led to many discussions throughout the organization, including the lessons learned and how to strategize with governments, the WHO, and other global organizations to prevent such catastrophic consequences during future infectious disease outbreaks. As Jason Cone recently told the JCI, "How do we, as an organization, manage so many emergencies at once? How do we work with novel pathogens? Even with something like Ebola, we had a pretty good level of understanding of how it was transmitted. How are we going to deal with something that's transmitted differently?" As MSF looks to the future, the priority is and will remain providing care for patients first. The 2015 Lasker Bloomberg Public Service Award recognizes this extraordinary organization for their leadership and dedication to serving and caring for people in crisis throughout the world.

\section{Corinne L. Williams}

1. MSF history. MSF Web site. http://www.msf.org/ msf-history. Accessed August 21, 2015.

2. Ebola: Pushed to the limit and beyond. MSF Web site. http://www.msf.org/article/ebola-pushedlimit-and-beyond. Published March 23, 2015. Accessed August 21, 2015.

3. Johnson KM, Lange JV, Webb PA, Murphy FA. Isolation and partial characterisation of a new virus causing acute hæmorrhagic fever in Zaire. Lancet. 1977;309(8011):569-571.

4. To KK, Chan JF, Tsang AK, Cheng VC, Yuen KY. Ebola virus disease: a highly fatal infectious disease reemerging in West Africa. Microbes Infect. 2015;17(2):84-97.

5. Peters CJ, LeDuc JW. An introduction to Ebola: the virus and the disease. J Infect Dis. 1999;179(suppl 1):ix-xvi.

6. Alexander KA, et al. What factors might have led to the emergence of Ebola in West Africa? PLOS Negl Trop Dis. 2015;9(6):e0003652.

7. Guinea: Mobilisation against an unprecedented Ebola epidemic. MSF Web site. http://www.msf. org/article/guinea-mobilisation-against-unprecedented-ebola-epidemic. Published March 31, 
2014. Accessed August 21, 2015.

8. Ebola in West Africa: Epidemic requires massive deployment of resources. MSF Web site. http://www.msf.org/article/ebola-west-africaepidemic-requires-massive-deploymentresources. Published June 21, 2014. Accessed August 21, 2015.

9. Operational Update: The Ebola outbreak in West Africa. MSF Web site. http://www.msf. org/article/operational-update-ebola-outbreakwest-africa. Published July 24, 2014. Accessed August 21, 2015.

10. Emergencies preparedness, response. Ebola virus disease update - West Africa. WHO Web site. http://www.who.int/csr/don/2014_08_08 ebola/en/. Published August 8, 2014. Accessed August 21, 2015.
11. Ebola: the failures of the international outbreak response. MSF Web site. http://www.msf.org/ article/ebola-failures-international-outbreakresponse. Published August 29, 2014. Accessed August 21, 2015.

12. Liberia: MSF's new Ebola management centres already overwhelmed. MSF Web site. http://www.msf.org/article/liberiamsf\%E2\%80\%99s-new-ebola-managementcentres-already-overwhelmed. Published August 27, 2014. Accessed August 21, 2015.

13. MSF President's remarks to the UN Special Briefing on Ebola. MSF Web site. http://www.msf. org/article/msf-presidents-remarks-un-specialbriefing-ebola. Published September 16, 2014 Accessed August 21, 2015.

14. Ebola data and statistics. Situation summary.
WHO Web site. http://apps.who.int/gho/data/ view.ebola-sitrep.ebola-summary-20141231. Published December 31, 2014. Accessed August 21, 2015.

15. Ebola Situation Report-12 August 2015. WHO Web site. http://apps.who.int/ebola/currentsituation/ebola-situation-report-12-august-2015. Accessed August 21, 2015.

16. Media centre. The Ebola outbreak in Liberia is over. WHO Web site. http://www.who.int/mediacentre/news/statements/2015/liberia-endsebola/en/. Published May 9, 2015. Accessed August 21, 2015.

17. Liu J. Attention, world: The Ebola fight isn't over TIME Web site. http://time.com/3994353/ebolaepidemic-msf/. Published August 12, 2015. Accessed August 21, 2015. 